\title{
Article \\ Modelling of Auxetic Woven Structures for Composite Reinforcement
}

\author{
Shivangi Shukla ${ }^{1}$, Bijoya Kumar Behera ${ }^{1}$, Rajesh Kumar Mishra ${ }^{2, * \mathbb{D}}$, Martin Tichý ${ }^{2}$ (D) , Viktor Kolár̆ ${ }^{2} \mathbb{D}$ \\ and Miroslav Müller ${ }^{2}$ iD
}

1 Department of Textile \& Fiber Engineering, Indian Institute of Technology Delhi, New Delhi 110016, India; shiwangishukla112@gmail.com (S.S.); behera@textile.iitd.ac.in (B.K.B.)

2 Department of Material Science and Manufacturing Technology, Faculty of Engineering, Czech University of Life Sciences Prague, Kamycka 129, 16500 Prague, Czech Republic; martintichy@tf.czu.cz (M.T.); vkolar@tf.czu.cz (V.K.); muller@tf.czu.cz (M.M.)

* Correspondence: mishrar@tf.czu.cz

check for updates

Citation: Shukla, S.; Behera, B.K.; Mishra, R.K.; Tichý, M.; Kolář, V.; Müller, M. Modelling of Auxetic Woven Structures for Composite Reinforcement. Textiles 2022, 2, 1-15. https://doi.org/10.3390/ textiles2010001

Academic Editor: Stepan Lomov

Received: 8 November 2021

Accepted: 24 December 2021

Published: 27 December 2021

Publisher's Note: MDPI stays neutral with regard to jurisdictional claims in published maps and institutional affiliations.

Copyright: (C) 2021 by the authors. Licensee MDPI, Basel, Switzerland. This article is an open access article distributed under the terms and conditions of the Creative Commons Attribution (CC BY) license (https:// creativecommons.org/licenses/by/ $4.0 /)$.

\begin{abstract}
The current research is focused on the design and development of auxetic woven structures. Finite element analysis based on computational modeling and prediction of axial strain as well as Poisson's ratio was carried out. Further, an analytical model was used to calculate the same parameters by a foldable zig-zag geometry. In the analytical model, Poisson's ratio is based on the crimp percentage, bending modulus, yarn spacing, and coefficient of friction. In this yarn, properties and fabric parameters were also considered. Experimental samples were evaluated for the actual performance of the defined auxetic material. Auxetic fabric was developed with foldable strips created in a zig-zag way in the vertical (warp) direction. It is based on the principle that when the fabric is stretched, the unfolding of the folds takes place, leading to an increase in transverse dimensions. Both the analytical and computational models gave close predictions to the experimental results. The fabric with foldable strips created in a zig-zag way in the vertical (warp) direction produced negative Poisson's ratio (NPR), up to $8.7 \%$ of axial strain, and a maximum Poisson's ratio of -0.41 produced at an axial strain of around $1 \%$. The error percentage in the analytical model was $37.14 \%$ for the experimental results. The computational results also predict the Poisson's ratio with an error percentage of $22.26 \%$. Such predictions are useful for estimating the performance of auxetic woven structures in composite reinforcement. The auxetic structure exhibits remarkable stress-strain behavior in the longitudinal as well as transverse directions. This performance is useful for energy absorption in composite reinforcement.
\end{abstract}

Keywords: auxetic woven structures; negative Poisson's ratio (NPR); axial strain; finite element modeling (FEM); equivalent stress; total deformation; analytical modeling

\section{Introduction}

Auxetic structures belong to a class of extraordinary materials that become thicker in the perpendicular direction when it is stretched longitudinally. In other words, these materials exhibit negative Poisson's ratio (NPR) and therefore show perceptible improvement over conventional materials in toughness, resilience, shear resistance, and acoustic properties mainly due to their special structure and associated deformation mechanics [1-5]. Research has shown that the auxeticity of a structure depends on its geometrical arrangement and the way it deforms under the action of external force. Zero Auxeticity describes the state when the material is stretched in the longitudinal direction and there is no change in the transverse direction, that is, neither contraction nor expansion. In various studies in the literature, it has been reported that auxeticity can be introduced on all scales making it scale-independent. Auxetics can be broadly categorized into two categories, natural and synthetic, based on their origin [6-13]. Certain natural auxetic materials have been reported like the cancellous bone in humans [14], cow teat skin, cat skin, and salamander 
skin [15-17], iron pyrite mono crystal [18], zeolites [19,20], silicates, thermal graphite, rocks with micro-cracks in the structure, arsenic with a single crystalline structure [21], cadmium [22], and alpha cristobalite silica crystal [23]. Auxetic material exhibits a wide range of properties like resistance to shear, fracture, indentation, acoustic absorption, impact energy absorption, etc. which makes it suitable for various applications like protective clothing equipment, automobiles [16], acoustic theatres [24,25], composites [26-28], etc. Some of the auxetics cannot be used for heavy load-bearing applications, as they are porous $[29,30]$ but contradicting this statement, researchers have reported that nearly $70 \%$ of the cubic crystals possess auxeticity [13]. It has been reported that Poisson's ratio of isotropic materials is independent of the direction of application of force, that is, the deformation of a material in the direction of one axis will produce a deformation of the material along the other axis in three dimensions, whereas, in the case of anisotropic material, the value of Poisson's ratio depends on the direction of extension and transverse deformation. There is a category of materials called partial auxetic, that is, they exhibit auxeticity only in some directions [31]. In textiles, the production of auxetic materials is possible in the form of fiber, yarn, fabric, and their composites [32]. Auxetic composites have attracted considerable attention in recent years and have demonstrated a high potential of applications in different areas due to their wonderful properties as compared to non-auxetic composites [33-40]. In fabric, the auxetic structure can be produced by knitting, nonwoven, and weaving process [41]. Production of auxetic woven fabrics is possible in three ways; using auxetic yarn with conventional weave design [42,43], using auxetic weave design with conventional yarn, and by using the combination of auxetic yarn and auxetic weave design [44]. In conventional yarns, different combinations of yarns in weft and warp yarns are used for developing auxetic fabric. The benefit of using conventional yarns for making the auxetic fabric is that they have high structural stability than auxetic fiber. When they have stretched, the tendency to recover to their original structure is low due to the interlacement of warp and weft yarns. Due to this, their fabrication and usage as yarn to produce fabric are challenging.

There are many ways by which auxetic composite formation can be performed from the woven auxetic preforms. Researchers have used the hand lay-up method to the vacuumassisted resin transfer molding (VARTM) process for the manufacturing of auxetic composites $[45,46]$. The choice of matrix system is very crucial in the manufacturing of auxetic composites, as in some cases, the matrix system can cause resistance to the movement of the reinforcing structure, leading to a reduction in the NPR value of the composites. Various matrix systems like epoxy, soft polyurethane, and silicone rubber have been used in the past $[26,27,47-49]$. The auxetic reinforcement may be used in different forms varying from fiber to fabric. Textile fibers can be transformed into a broad range of structures such as yarns, fabrics, cloth, and composites by utilizing various textile manufacturing technologies like spinning, weaving, knitting, braiding, and textile structural composite processing. These manufacturing processes feature the grounds for satisfying the needs of contemporary societies as they help to transform raw materials into finished products incorporating organized and engineered structures. However, the specific properties of these products can be achieved only by judicious use of the engineering design principle. Modeling is an efficient way to represent a real-life engineering problem, and the result obtained from modeling can be generally used for the construction and prediction of the properties of the system or assembly. A model is also used to understand a complex system with the help of simplifications and assumptions. Thus, for auxetic materials and structures, modeling can be done by different methods.

In this research, both analytical and computational modeling methods are used to predict the NPR value of woven fabric produced with the help of conventional yarns in auxetic weave geometry. Fabric samples were produced, and their Poisson's ratio was determined to validate the predicted NPR values. The results are useful for predicting the load-bearing capacity and energy absorption in a composite reinforced with auxetic woven structures. 


\section{Analytical Model}

To develop the analytical model, a foldable zig-zag geometry as shown in Figure 1 was considered for the formation of a woven construction. The basic unit cell design that is to be geometrically analyzed is shown in Figure 2.

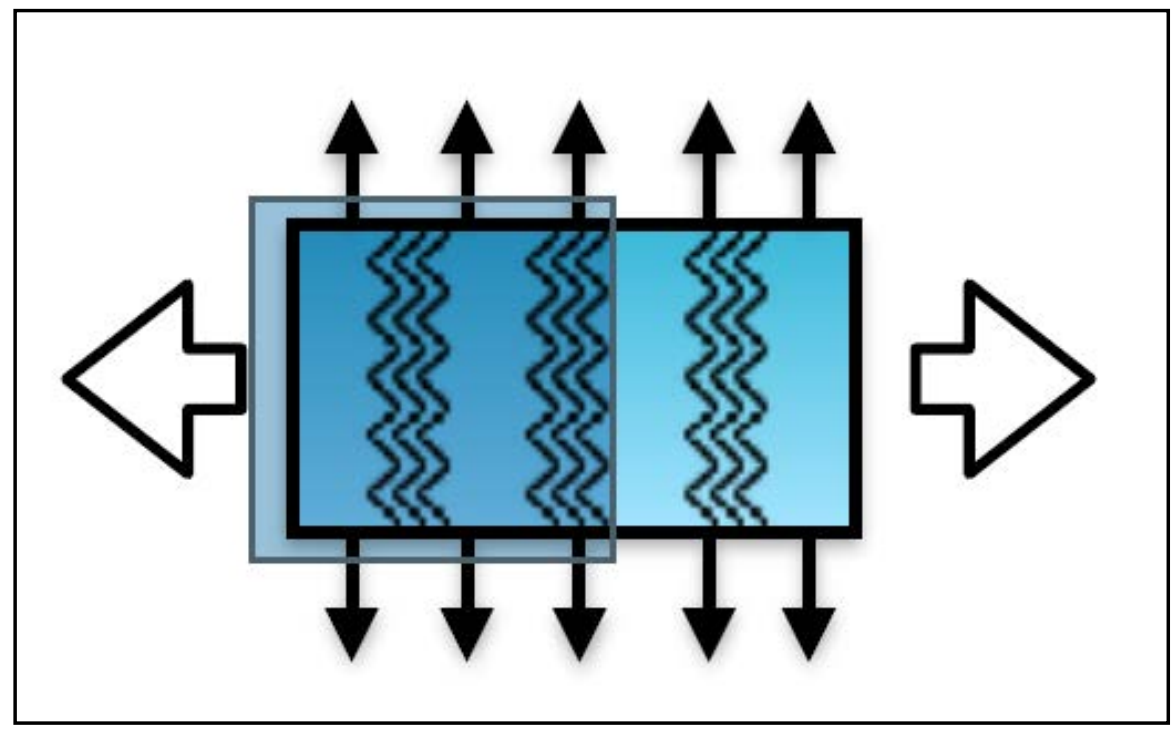

Figure 1. Foldable strips in a zig-zag way along the warp.

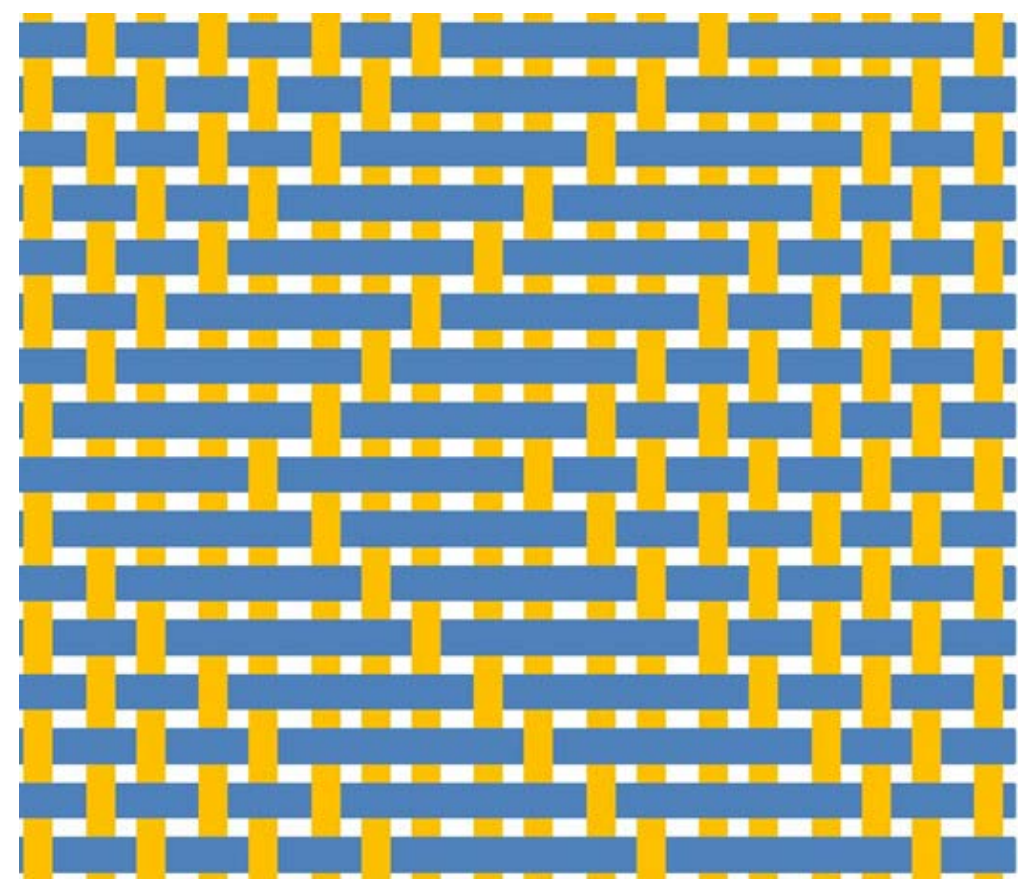

Figure 2. Unit cell of auxetic weave design.

The combination of plain weave and float is used to generate the desired auxetic design as shown in Figure 2. In this design, when the structure is pulled along the direction of the warp, it tries to open the fold and expands the fabric in the transversal direction. It is assumed that two different types of yarns are used in the weft with elasticity, $E_{l}$ and $E_{s}$, and elasticity of warp yarn be $E_{p}$.

In the unit cell of the design, there are 18 warp and 17 weft yarns. Considering each pick, there are two portions of different weave patterns, for example, the first weft is interlaced with nine warp yarns in a plain weave pattern, and the rest is with 1-up-4-down 
twill (float). The weft has two yarns that are elastic and stiffer yarn. The elastic yarn will be responsible for the extension in the floating part initially. The pull-out force of yarn from a plain-woven fabric is much more compared to that of 1 up 4 down twill weaves, as the interlacements in the case of plain weave are more. The stiffer weft yarn would require force to overcome the friction resistance. The stress at both sides of the fabric is equal and varying as the rate of displacement of the ends of the fabric is constant. Solving for the first pick, there are two segments-plain weave and float-the plain weave is toward the left side of the line of center. The force on both sides (connecting point) of the portion is different due to the non-symmetry of the structure. The force acting on the right side of the plain weave part would be more than on the left side. This would be balanced by the frictional force at each contact, which would accumulate in one direction due to differences in the end forces. The frictional force at each contact point in plain weave and float is given by Pan [50] as shown in Equations (1)-(3).

$$
\begin{gathered}
F_{f}=\mu P \\
P=2 \sigma \sin \theta_{p w}(\text { For uniform plain weave }) \\
P=\frac{6 \sigma \sin \theta_{f}}{5}(\text { For float } 2 / 1 \text { twill weave })
\end{gathered}
$$

where $P$ is the compression force acting on the point of intersection of warp and weft yarns, $\theta$ is the weave angle, and $\sigma$ is the applied stress, $\mu$ is coefficient of friction, where $p w$ stands for plain weave, and $f$ stands for float region.

Figure 3 refers to a symbolic representation of interlaced (rigid region) and noninterlaced (loose region) areas. The float portion would be experiencing an extra force in the left that would not be balanced by its frictional force as shown in Figure 3 . Figure 4 demonstrates a line diagram for the weave, where the zig-zag solid line denotes the point of interlacement of warp and weft, and the space between them constitutes the float area. The dotted line refers to the line connecting the midpoints of the twill line. This will move the center of the float towards the line of center. From Figure 4, the floating part gets another extra force towards the left due to the difference of accumulated friction force of the plain weave and float part; point A moves toward the line of center. After analyzing the single weft, while stretching, the center of the float will deflect toward the side (w.r.t line of center) where there is a significant portion of plain weave surrounding the float. Point $B$ will move towards the line of the center from the left and point $C$ will travel towards the line of the center from the right. All the weft in between point A, B, C will follow the course according to the argument as mentioned earlier and the center of float in each weft will try to come closer towards each other in the axial direction. The virtual line $\mathrm{AB}$ and $\mathrm{BC}$ would be formed where all the center of floats will lie on that line, and their tendency of motion will force the acute angle between the lines to overlap with the line of center. This is due to couple formation in the virtual lines $A B$ and $B C$ individually which restricts the motion of point $B$ in the $y$-axis (weft direction). Point $B$ transfers its component force to the lines $\mathrm{AB}$ and $\mathrm{BC}$ in upward and downward directions, respectively.

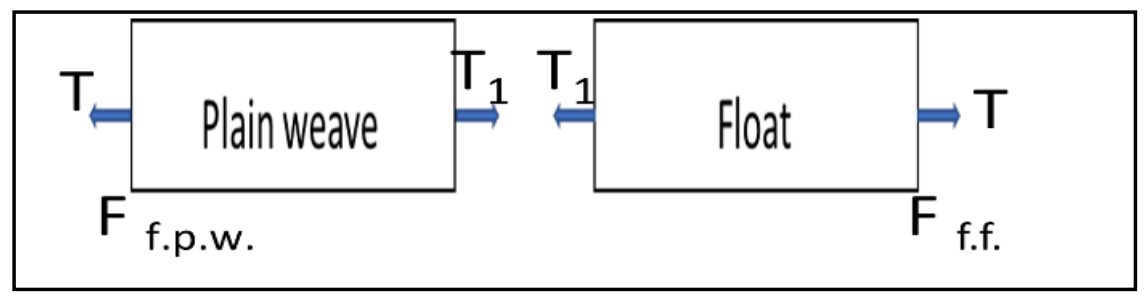

Figure 3. Free body diagram of loading. (T: Outward Tension, $\mathrm{T}_{1}$ : Inward tension, F: Total frictional force, f.p.w: friction on plain weave, f.f: friction on float). 

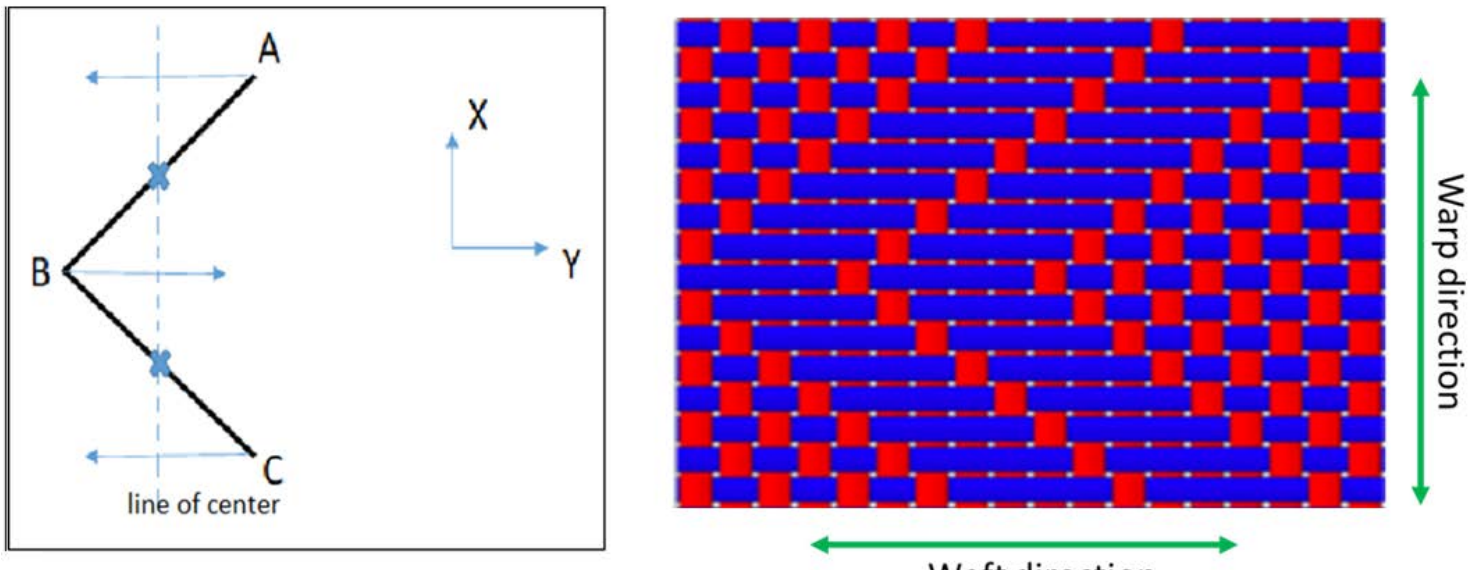

Weft direction

Figure 4. Couple formation in auxetic structure. (A, B, C: are nodal points of the zigzag pattern, X, Y: are axes representing warp and weft respectively).

The extension in the plain weave that would contribute to the overall extension of fabric in the axial direction would be due to the stiffer part (de-crimping) and the extension in the elastic yarn would be the same as of stiffer yarn due to interlacement present in the plain weave. The extension in that part would be according to the saw teeth model as shown in Figure 5, which is a representation of the unit cell of interlacement of warp and weft. where applied forces are not large, considering the bending energy. This analysis is useful for understanding the initial extension and de-crimping of the fabric under uniaxial load.

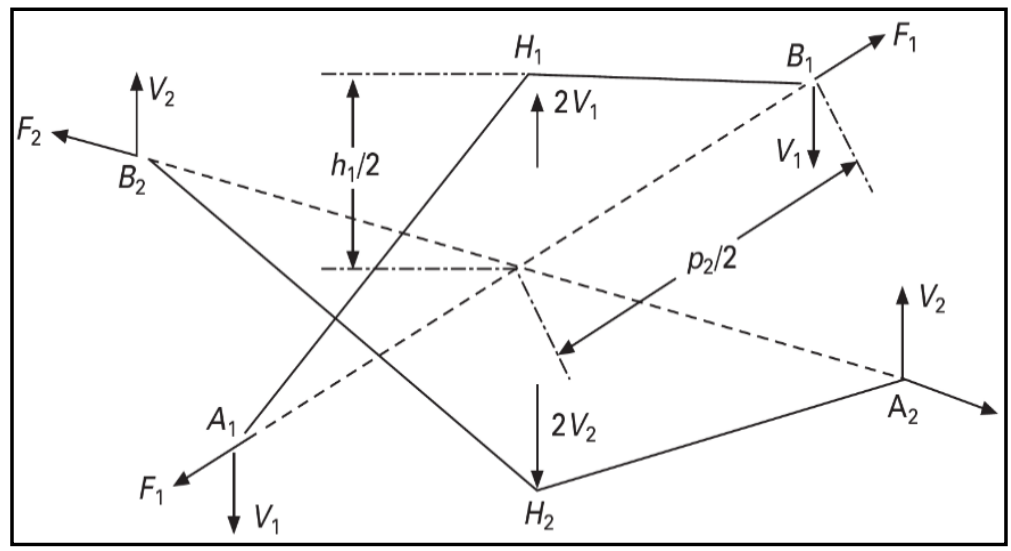

Figure 5. Saw tooth model for plain weave. $\left(A_{1}, A_{2}, B_{1}, B_{2}\right.$ : are nodal points of the saw tooth model, $H_{1}, H_{2}$ : are crimp amplitudes in $\mathrm{X}$ and $\mathrm{Y}$ axes, $h_{1} / 2$ : crimp height from crossover point, $F_{1}, F_{2}$ : Total force along the saw tooth axes, $p_{2} / 2$ : half wavelength, $V_{1}, V_{2}$ : inter yarn pressure).

All these notations refer to Figure 5, where the $p$ is the spacing between the yarns, $V$ is the inter-yarn pressure at crossover points (here $V=\mathrm{P}$ ), $h$ is the crimp height, it is otherwise called crimp amplitude where the amplitude is the maximum displacement of yarn from the central axis. It may be mentioned that crimp in the yarn of woven fabric makes a waveform, $B$ is the bending rigidity of the yarn, $l$ refers to the length of yarn between two consecutive crossover points, 1 and 2 represent warp and weft, respectively. Accordingly, to this model, the extension in the warp direction is given by

$$
\delta p_{1}=\frac{l_{2} h_{2}\left(F_{2} h_{2}-V_{1} p_{2}\right)}{l_{2} B_{1}}
$$

The final extension in the plain weave part is multiplied by the number of plain weave interlacements $(n)$ 


$$
\delta x_{1}=(n-1) \times \delta p_{1}
$$

The extension in the floating part would be because the elastic yarn is in taut condition and the stiffer yarn is in slack condition. The float is extended till the stiffer yarn is in a taut condition.

$$
\begin{aligned}
\epsilon & =\frac{\Delta F_{f}}{E_{l}} \\
\delta x_{2} & =\frac{\Delta F_{f}}{E_{l}} L
\end{aligned}
$$

where $\Delta F_{f}$ the difference in the force of friction of the two portions, $L$ is the float length, $E_{l}$ is the elasticity of the weft yarn, $\delta x_{2}$ is the final extension in the float region. Now, the total extension would be the sum of extension in the plain weave and float part. The strain in the axial direction is total extension divided by the length of the fabric (in this case unit cell).

Now, considering the forces that are acting on warp yarns, as there is no external stress applied in the transversal direction, the frictional force, and the transferred force due to the restricted motion of Point B would be in action. In the warp yarn also, there is a tightly woven and loosely woven part. Solving for the warp containing point A and C, the extension in plain weave is

$$
\delta p_{2}=\frac{l_{1} h_{1}\left(\Delta F_{f} h_{1}-V_{2} p_{1}\right)}{l_{2} B_{2}}
$$

The float will also extend according to the same argument but with a different compression force. Similarly, we add the extension of both the sections and dividing by the total length of warp yarn. The strain in the transverse direction would be positive and finally, the Poisson's ratio would be negative until the tension (applied force) becomes too large to decrease the angle of the weave to zero. After this point, Poisson's ratio becomes positive because the yarn extension and strength come into the role. The above model is valid for the tension less than the critical point.

\subsection{Material}

Auxetic fabric is developed with foldable strips created in a zig-zag way in a vertical (warp) direction. It is based on the principle that when the fabric is stretched unfolding of the folds takes place, leading to an increase in transverse dimensions. Foldable geometry was realized into the fabric using a combination of loose and tight weaves to create differential shrinkage [14-17]. The unit cell of interlacement pattern of two single-layered fabrics based on parallel in-phase zigzag alternately folded stripes running along the warp direction as shown in Figure 6.

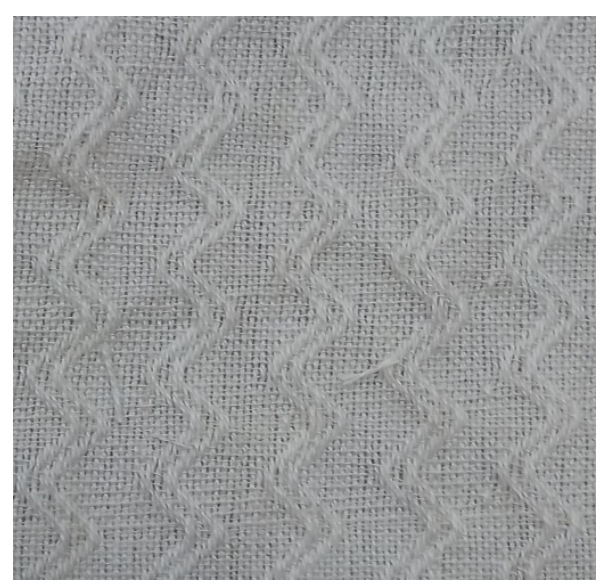

Figure 6. Auxetic woven fabric sample. 
The yarn used as weft was elastic (core spun spandex) with a fineness of 38 tex and non-elastic yarn (cotton) with a fineness of 20 tex. The yarn in the warp was non-elastic yarn (cotton) with a fineness of 2/30 tex. These yarns are used to exploit the differential shrinkage effect. The thread density in both directions is $16 / \mathrm{cm}$. Mainly three types of yarns are used to exploit the auxetic nature of the developed fabric. The stretch properties of these yarns are presented in Table 1.

Table 1. Yarn properties.

\begin{tabular}{|c|c|c|c|}
\hline S.No & Yarn Fineness & $\begin{array}{c}\text { Tenacity at Breaking Extension } \\
\text { (cN/tex) }\end{array}$ & $\begin{array}{c}\text { Breaking Extension } \\
(\%)\end{array}$ \\
\hline A & Cotton $(30 / 2$ tex $)$ & 13.608 & 6.304 \\
\hline $\mathrm{B}$ & Cotton (20 tex) & 11.890 & 3.404 \\
\hline $\mathrm{C}$ & Core spun spandex 38 tex & 5.674 & 63.24 \\
\hline
\end{tabular}

\subsection{Test Method}

Testing of all the specimen samples is performed on a video extensometer shown in Figure 7. The video extensometer is designed to accurately measure specimen strain during a materials test without the need to contact the specimen. The non-contacting measuring process leads to no mechanical influence on the specimen, ease of use, and reproducibility. The developed fabric has extensibility in one direction therefore test was carried out along this direction however the fabric can be tested along the warp direction but due to the limited extensibility in this direction, the fabric may break at smaller strain and cannot be tested over a wider range of strain.

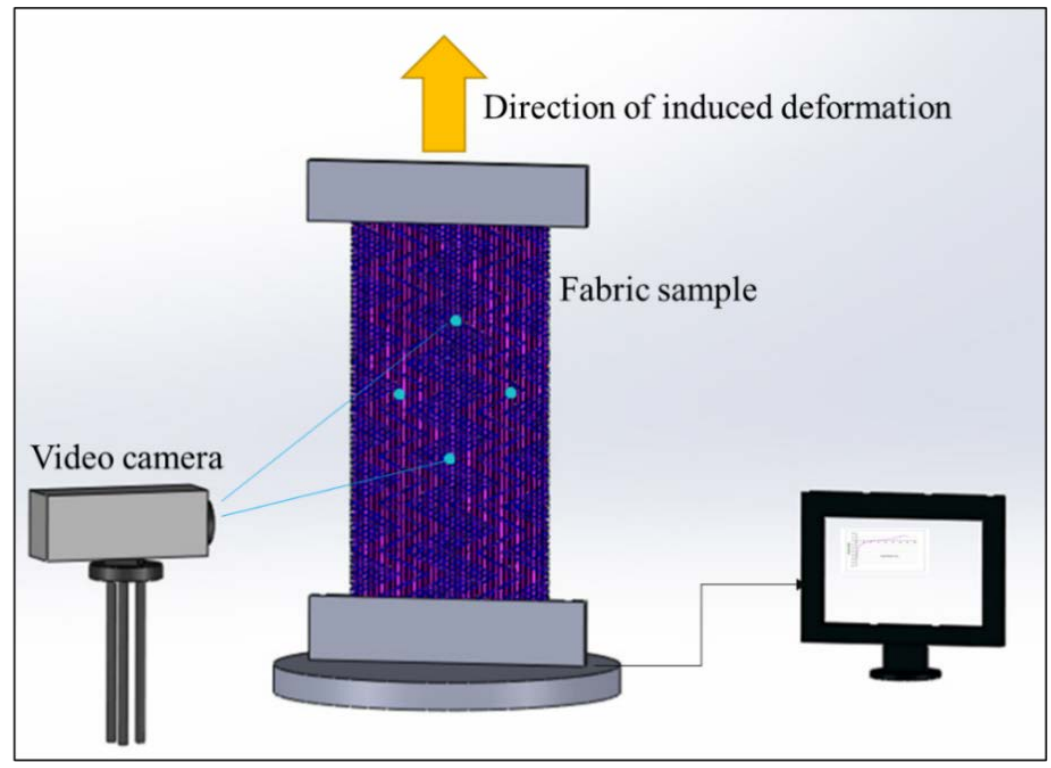

Figure 7. Experimental setup to determine Poisson's ratio.

The tensile test was conducted on an Instron 5982 tensile machine. The capacity of the load cell used was $100 \mathrm{kN}$. The tensile speed and the gauge length were set as $50 \mathrm{~mm} / \mathrm{min}$ and $100 \mathrm{~mm}$ respectively. Fabric strips of dimension $(100 \mathrm{~mm} \times 50 \mathrm{~mm})$ were cut for each sample. Four points were marked by keeping the scale at the center of the fabric at a $25 \mathrm{~mm}$ distance to simplify the recording of the information of the fabric deformation during the tensile test. The distances of the two marks in the tensile and the traversal directions were scanned by a camera to record the extension for each sample until the sample broke and the software of the machining process the data to calculate the engineering strain of fabric in both tensile directions and the traversal directions. The fabric parameters are given in Table 2. 
Table 2. Fabric Parameters.

\begin{tabular}{ccc}
\hline Parameters & Warp & Weft \\
\hline Yarn spacing (mm) & 0.635 & 0.635 \\
Crimp (\%) & 8 & 7.1 \\
Bending modulus (MPa) & 0.53 & 0.53 \\
Coefficient of friction & 0.1 & 0.1 \\
\hline
\end{tabular}

\section{Computational Model}

For the computational modeling of the foldable woven fabric, the unit cell of the model is firstly created on Texgen software, according to the weave design. Texgen can create a wide variety of 2-D and 3-D weaves [1]. Here, the yarns are considered as single unit, that is, solid volumes instead of considering the fiber in the yarns as individual units.

Geometry: The unit cell shown in Figure 8, is created by varying the float length along the warp and weft direction. Here, we use a combination of the plain weave along with the 4 up 1 down twill weave. Here, in each weft, 9 warp yarns are interlaced in plain weave and 10 warp yarns are interlaced in a $4 / 1$ twill pattern, forming a foldable geometry. The twill weave forms the folded part with a long float length, which unfolds when extended in the axial direction. The unit cell created in Texgen, when joined, can produce full-scale fabric. This sort of portrayal is significantly more helpful for computational analysis of material properties.

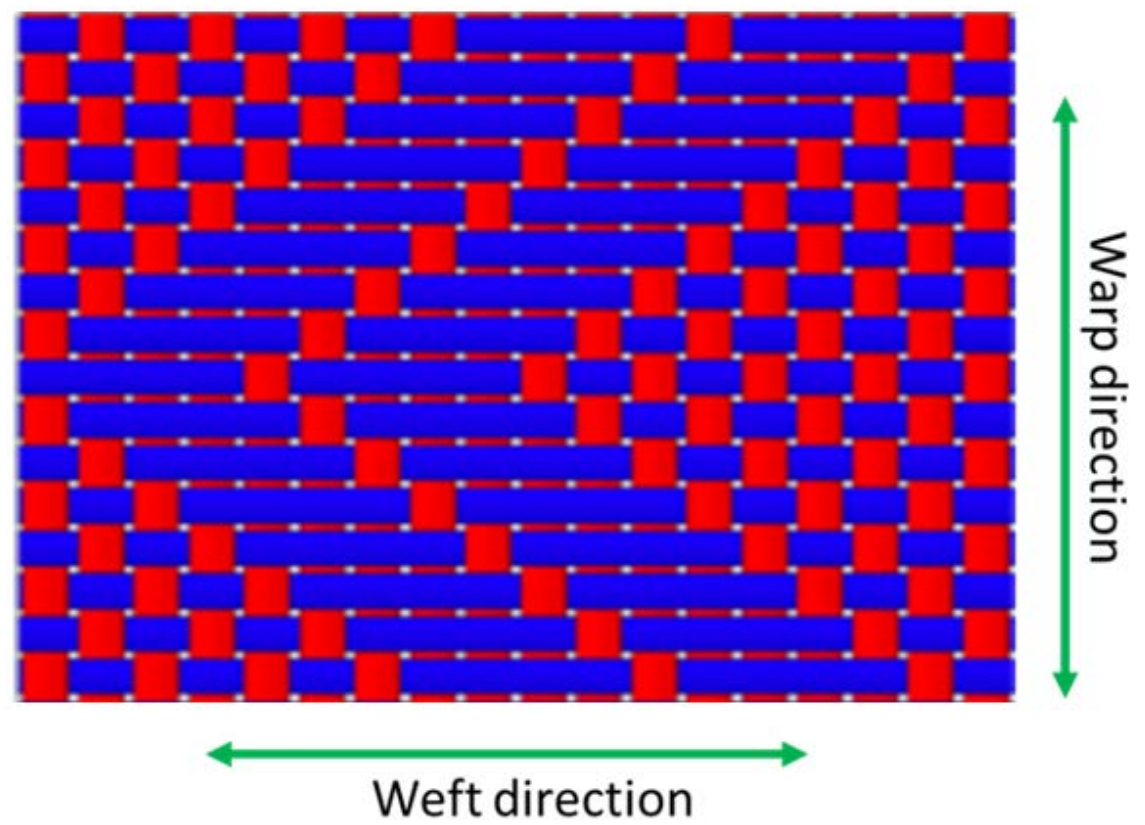

Figure 8. Texgen weave design for the auxetic structure.

FEM: The prepared unit cell is imported to Ansys Workbench as a Stereo Lithography file to FEM Modeler to generate the initial geometry. Then these data are transferred to the transient structural feature. Then the type of material is assigned to the yarns, that is, the weft yarns were kept elastic and warp yarns are kept non-elastic.

Contact: Initially the contact is created automatically on Ansys mechanical, analyzing the face-to-face detection shown in Figure 9 but the contacts are modified according to weave design. The contact method is changed to frictional with the coefficient of friction equal to 0.1. The formulation is set to Augmented Lagrange as the penetration matter in this model. The initial contact condition is analyzed through the contact tool and accordingly pinball radius is adjusted manually. 


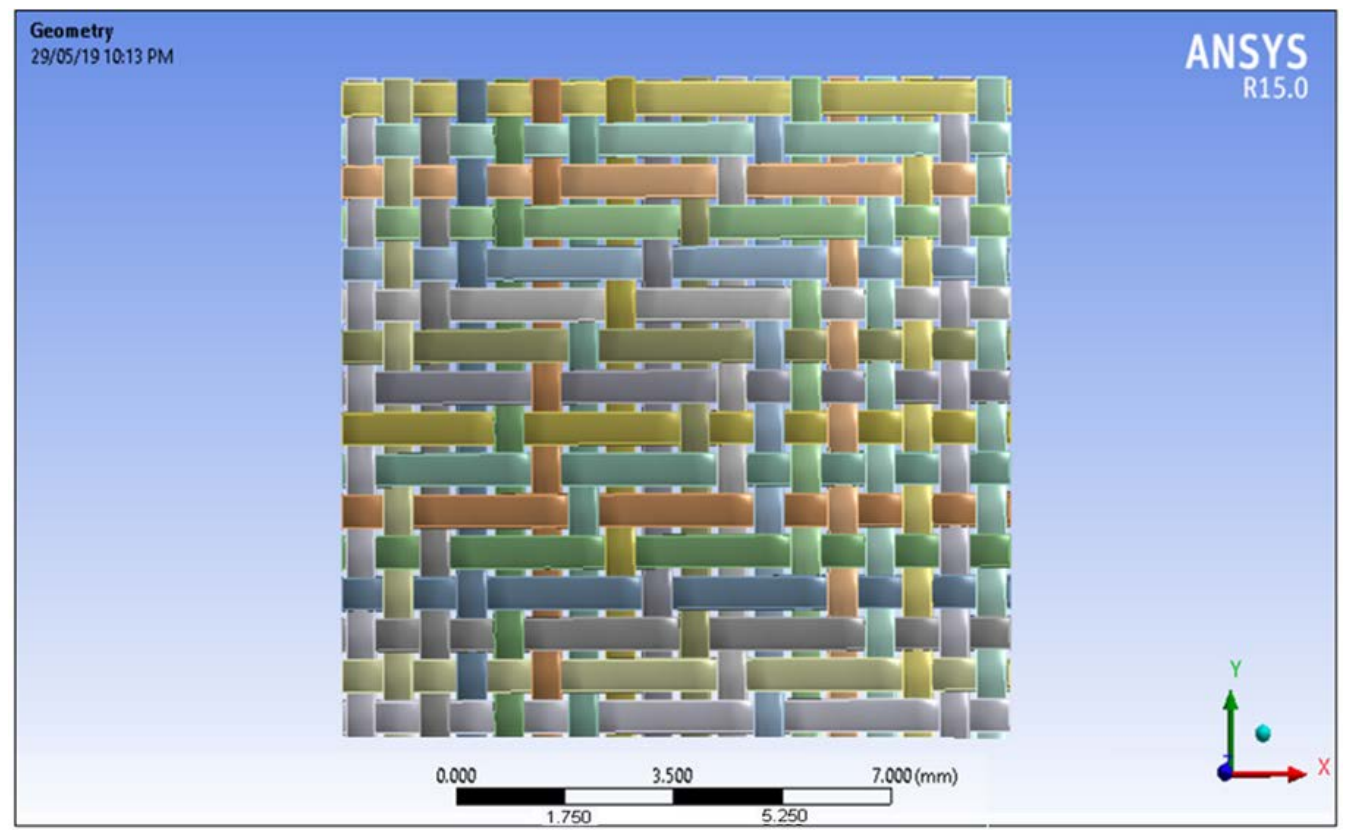

Figure 9. Contact definition in the model.

Mesh generation: After the contact point generation, the mesh was generated as shown in Figure 10. The mesh size taken here was medium for easy processing and accuracy and element size was $0.125 \mathrm{~mm}$ by default.

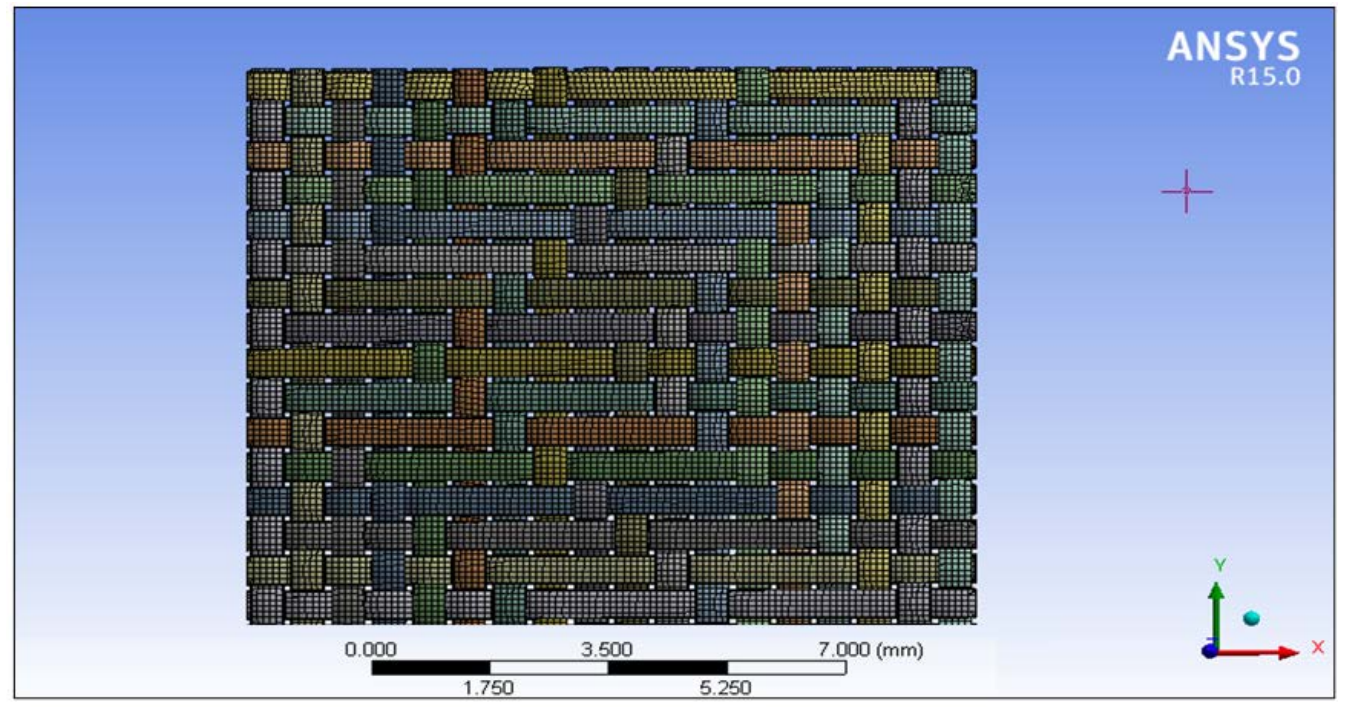

Figure 10. Mesh generation.

Boundary conditions: The boundary conditions are imposed, as shown in Figure 11, on the unit cell, keeping in mind that it is a repeating unit and not a full-scale fabric. The following kinematic boundary condition will be applied as in Equations (9) and (10).

$$
\begin{aligned}
& v_{1}-v_{2}=E\left(x_{2}-x_{1}\right) \\
& v_{3}-v_{4}=E\left(x_{4}-x_{3}\right)
\end{aligned}
$$

where $v_{1}, v_{2}, v_{3}$, and $v_{4}$ are displacement vectors of points on the edges of $1,2,3$, and 4 , respectively, and $x_{1}, x_{2}, x_{3}$ and $x_{4}$ are the absolute value of distances corresponding to displacement vectors $v_{1}, v_{2}, v_{3}$, and $v_{4}$. E stands for macroscopic strain tensor of the fabric [51-54]. 


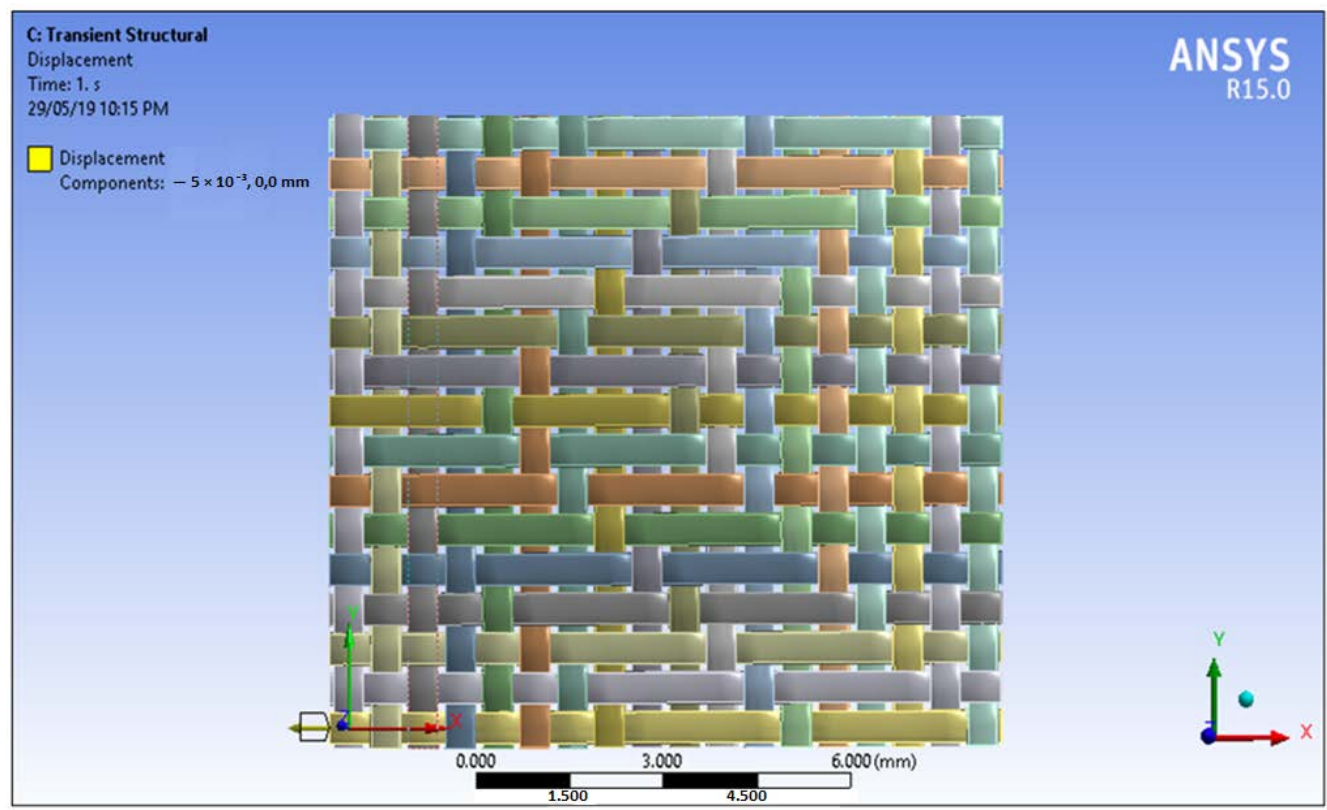

Figure 11. Boundary conditions.

Simulation: The left boundary was fixed along the $x$-direction and a directional displacement was applied along the right boundary, with the displacement rate of $2 \mathrm{~mm} / \mathrm{min}$. For the tensile test environment simulation, $\mathrm{z}$ and $\mathrm{y}$ directional displacements were constrained on both left and right boundaries. For the mechanical analysis of the model, elastic strain in the transverse direction in Figure 12.

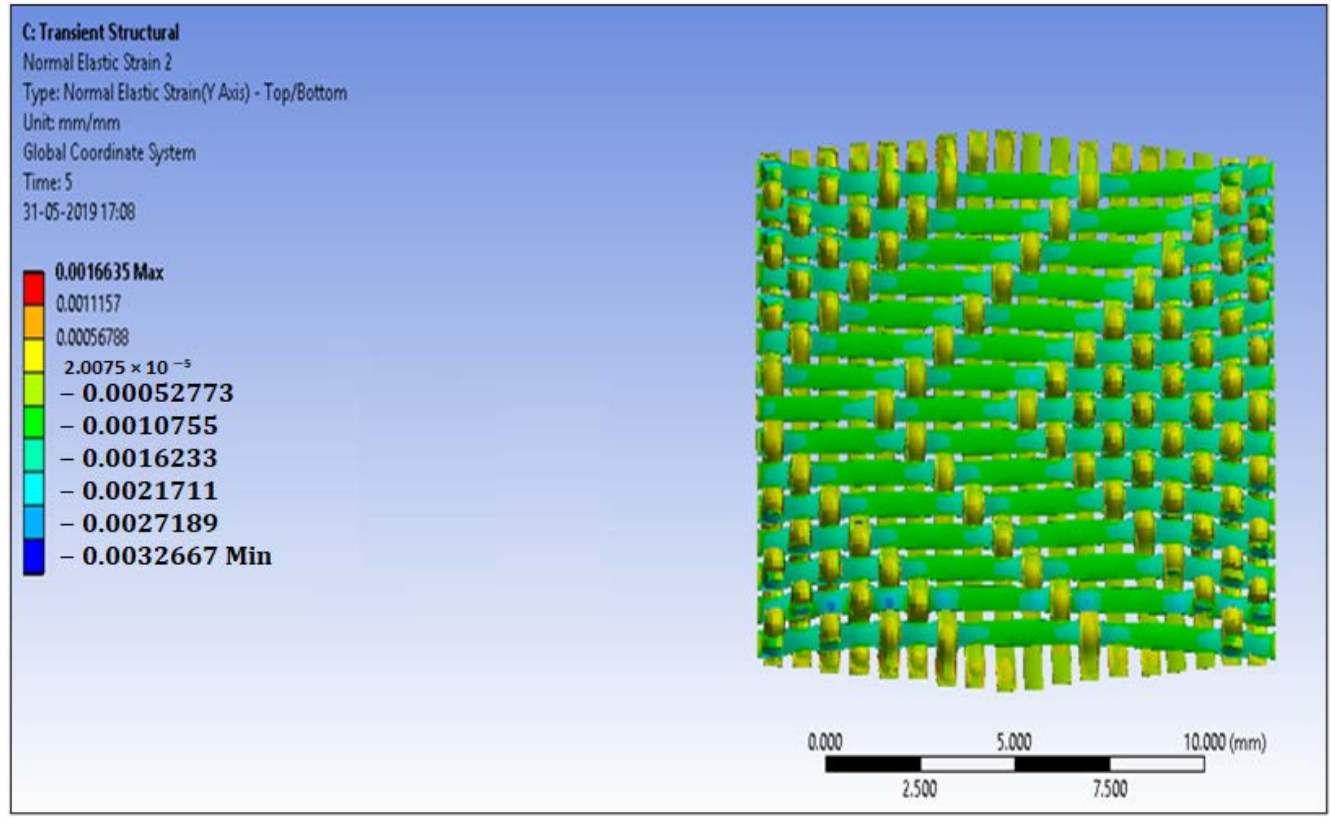

Figure 12. Elastic strain in the transverse direction.

\section{Results and Discussion}

The prepared fabric samples were tested for the tensile deformation under a video extensometer as shown in Figure 7. The Poisson's ratios at different axial strain were plotted. This experimental deformation behavior was compared with the results obtained from analytical and computational model results. The graphical representation of the NPR effect is shown as Poisson's ratio vs. axial strain values. 


\subsection{Experimental Results}

The poison's ratio was measured for the auxetic foldable design according to the procedure explained in Section 2.2. On analysis of Figure 13, it may be observed that fabric with foldable strips created in a zig-zag way in the vertical (warp) direction produced NPR up to $8.7 \%$ of axial strain and maximum Poisson's ratio of $(-0.41)$ produced at an axial strain of around 1\%. Although the NPR effect was lost when the strain percentage exceeded 9\%. The increase in Poisson's ratio with the increase of strain is due to the force of up-crimping in the traverse direction. This up-crimping is increasing as the applied load increases, resulting in the shrinking behavior of the sample in the transverse direction.

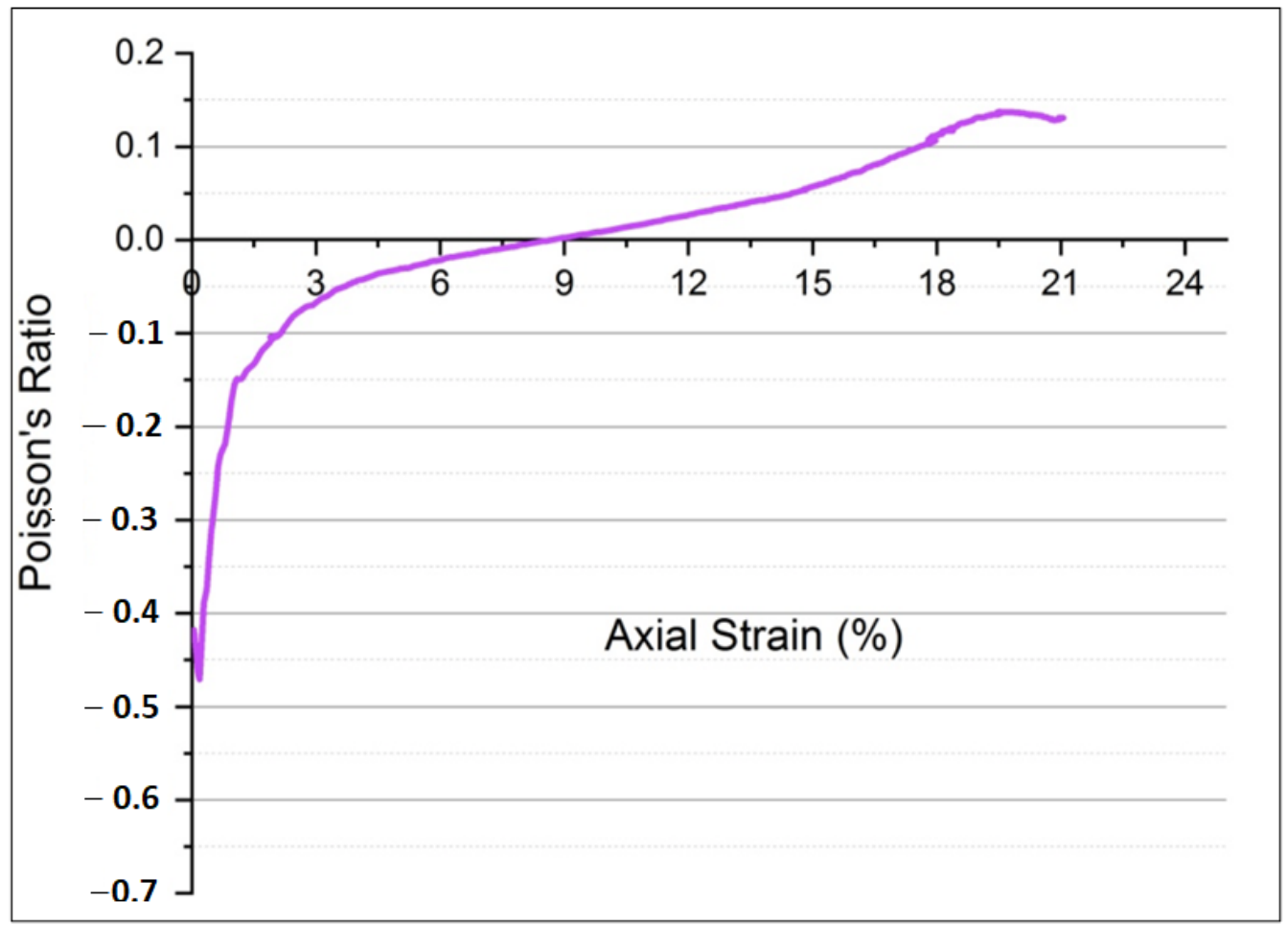

Figure 13. Experimental results of Poisson's ratio at different axial strain.

\subsection{Analytical Model Results}

The axial and transverse strain obtained by solving Equations [4-8] at tension $0.13296 \mathrm{~N}$ is given in Table 3. So, the maximum strain in the transverse direction is 0.000834 and the strain in the axial direction is 0.0014837 . The Poisson's ratio calculated from the above figures is -0.5623 . This value is calculated for a particular point, as the tension increases the $\sin (\theta)$ decreases leading to a change in Poisson's ratio. Drawing a continuous graph from the analytical model is difficult due to the non-linear dependence of $\theta$ on applied force. The above value calculated is at a particular value of applied force in which the maximum Poisson's ratio was obtained experimentally.

Table 3. Axial and transversal strain.

\begin{tabular}{ccc}
\hline Direction & Plain Weave & Float \\
\hline Weft (Axial strain \%) & 1.1660 & 0.5253 \\
Warp (Transverse strain \%) & 0.5268 & 0.3909 \\
\hline
\end{tabular}

\subsection{Computational Model Results}

The Poisson's ratio obtained through simulation data has a good relationship with the experimental data. Under unidirectional displacement, a series of quasi-uniform wave forms was observed in the transverse direction. Figure 14 shows that the value of Poisson's 
ratio is dependent on the extent of axial strain, that is, as the axial strain increases the NPR effect decreases. The trend observed here is close to the experiment values, the variation is due to the difference between contact simulations and actual contact conditions. From Figure 12, it was observed that the float region undergoes maximum elongation, due to the unrestricted motion of the elastic yarn. Moreover, the variation in the result is due to the weft yarn arrangement, that is, for actual fabric construction, alternate elastic and non-elastic yarns are used, whereas for the FEM simulation, consecutive elastic yarns are considered as the weft.

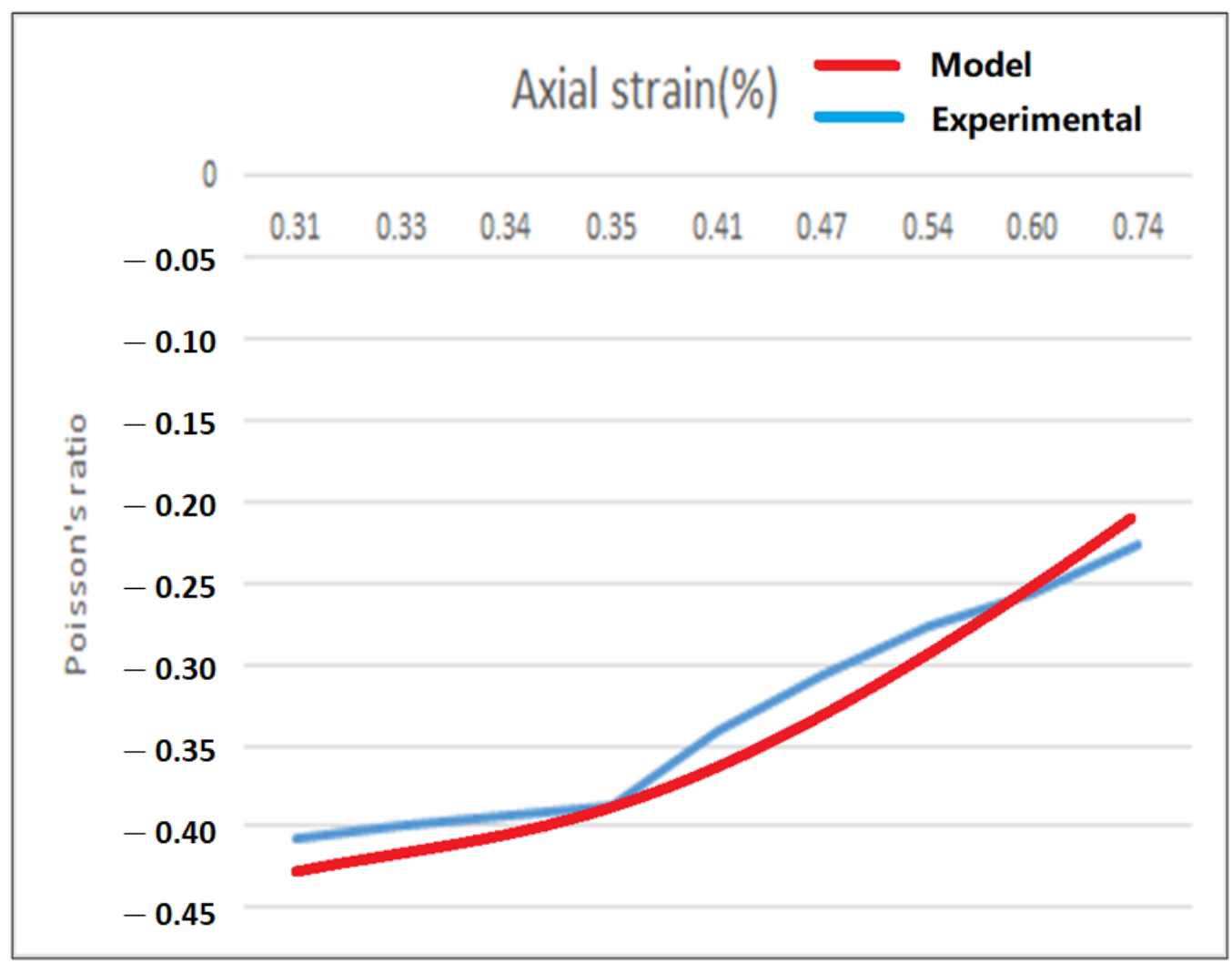

Figure 14. Computational model results vs. experimental results.

\subsection{Comparison of the Computational and Experimental Results}

From Figure 14, it was observed that the analytical model results are in good agreement with the experimental results despite having the limitation to predict the trend. The error percentage of the results of this model is $37.14 \%$ for experimental results. The computational results also predict the Poisson's ratio with an error percentage of $22.26 \%$. The reason for this error is the difference between the behavior yarn at interlacement points and this increases with the increase in the number of interlacements.

\section{Conclusions}

The analytical and computational model was built to predict the variation of Poisson's ratio of the auxetic fabric with the axial strain. The model was based on the unit cell of the foldable stripes created in a zig-zag way. In the analytical model, Poisson's ratio is based on the crimp percentage, bending modulus, yarn spacing, and coefficient of friction. In this yarn, properties and fabric, parameters were also considered. Also, successful computational modeling of the same was done. Both the analytical and computational models gave close predictions to the experimental results. It was observed that fabric with foldable strips created in a zig-zag way in vertical (warp) direction produced a negative Poisson's ratio (NPR) of $8.7 \%$. Poisson's ratio of $(-0.41)$ was produced at an axial strain of around 1\%. The NPR effect was lost when the strain percentage exceeded $9 \%$. 
The error percentage in the analytical model was $37.14 \%$ for experimental results. The computational results also predict the Poisson's ratio with an error percentage of $22.26 \%$. Such predictions are useful for estimating the performance of auxetic woven structures in composite reinforcement. The auxetic structure exhibits remarkable stress-strain behavior in longitudinal as well as transverse directions. This performance is useful for energy absorption in a composite reinforcement.

Author Contributions: S.S., B.K.B., R.K.M., M.T., V.K. and M.M., experiment design; S.S., B.K.B., R.K.M., M.T., V.K. and M.M., methodology; S.S., R.K.M., M.T. and V.K., testing of mechanical properties and data analysis; S.S., B.K.B. and R.K.M. wrote and edited the paper; B.K.B., R.K.M., M.T., V.K. and M.M., project administration; S.S., B.K.B. and R.K.M. language correction; B.K.B., R.K.M., M.T., V.K. and M.M., resources; R.K.M., communication with the editors; B.K.B., R.K.M. and M.M., supervision. All authors have read and agreed to the published version of the manuscript.

Funding: Supported by the Internal grant agency of Faculty of Engineering no. 2021:31140/1312/3108 "Experimental research of hybrid adhesive bonds with multilayer sandwich construction, Czech University of Life Sciences Prague".

Institutional Review Board Statement: Not applicable.

Informed Consent Statement: Not applicable.

Data Availability Statement: Not applicable.

Conflicts of Interest: The authors declare no conflict of interest.

\section{References}

1. Carneiro, V.H.; Meireles, J.; Puga, H. Auxetic materials-A review. Mater. Sci. Pol. 2013, 31, 561-571. [CrossRef]

2. Lim, T.C. Mechanics of Metamaterials with Negative Parameters; Springer: Heidelberg/Berlin, Germany, 2020. [CrossRef]

3. Gorodtsov, V.A.; Lisovenko, D.S. Auxetics among Materials with Cubic Anisotropy. Mech. Solids 2020, 55, 461-474. [CrossRef]

4. Lim, T.C. Auxetic Materials and Structures; Springer: Heidelberg/Berlin, Germany, 2015. [CrossRef]

5. Goldstein, R.V.; Gorodtsov, V.A.; Lisovenko, D.S. Classification of cubic auxetics. Phys. Status Solidi Basic Res. 2013, 250, 2038-2043. [CrossRef]

6. Zhou, S.; Li, Q. Microstructural design of connective base cells for functionally graded materials. Mater. Lett. 2008, 62, 4022-4024. [CrossRef]

7. Goldstein, R.V.; Gorodtsov, V.A.; Lisovenko, D.S.; Volkov, M.A. Auxetics among 6-constant tetragonal crystals. Lett. Mater. 2015, 5, 409-413. [CrossRef]

8. Goldstein, R.; Lisovenko, D.S.; Chentsov, A.; Lavrentyev, S.Y. Experimental study of auxetic behavior of re-entrant honeycomb with curvilinear elements. Lett. Mater. 2017, 7, 81-84. [CrossRef]

9. Lakes, R. Foam Structures with a Negative Poisson's Ratio. Science 1987, 235, 1038-1040. [CrossRef]

10. Wojciechowski, K.W. Two-Dimensional Isotropic System with a Negative Poisson Ratio. Phys. Lett. A 1989, 137, 60-64. [CrossRef]

11. Wojciechowski, K.W.; Tretiakov, K.V.; Kowalik, M. Elastic properties of dense solid phases of hard cyclic pentamers and heptamers in two dimensions. Phys. Rev. E 2003, 67, 036121. [CrossRef]

12. Goldstein, R.V.; Gorodtsov, V.A.; Lisovenko, D.S. Auxetic mechanics of crystalline materials. Mech. Solids 2010, 45, 529-545. [CrossRef]

13. Baughman, R.H.; Shacklette, J.M.; Zakhidov, A.; Stafström, S. Negative Poisson's ratios as a common feature of cubic metals. Nature 1998, 392, 362-365. [CrossRef]

14. Williams, J.; Lewis, J.L. Properties and an anisotropic model of cancellous bone from the proximal tibial epiphysis. J. Biomech. Eng. 1982, 104, 50-56. [CrossRef] [PubMed]

15. Frolich, L.M.; LaBarbera, M.; Stevens, W.P. Poisson's ratio of a crossed fibre sheath: The skin of aquatic salamanders. J. Zool. 1994, 232, 231-252. [CrossRef]

16. Pikhitsa, P.V. Architecture of cylinders with implications for materials with negative Poisson ratio. Phys. Status Solidi B-Basic Solid State Phys. 2007, 244, 1004-1007. [CrossRef]

17. Wang, Z.; Hu, H. Auxetic materials and their potential applications in textiles. Text. Res. J. 2014, 84, 1600-1611. [CrossRef]

18. Love, A.E.H. A Treatise on the Mathematical Theory of Elasticity. Nature 1920, 105, 511-512. [CrossRef]

19. Grima, J.N.; Gatt, R.; Zammit, V.; Williams, J.J.; Evans, K.E.; Alderson, A.; Walton, R.I. Natrolite: A zeolite with negative Poisson's ratios. J. Appl. Phys. 2007, 101, 086102. [CrossRef]

20. Bhullar, S.K. Three decades of auxetic polymers: A review. e-Polymers 2015, 15, 205-215. [CrossRef]

21. Gunton, D.J.; Saunders, G.A. The Young's modulus and Poisson's ratio of arsenic, antimony and bismuth. J. Mater. Sci. 1972, 7, 1061-1068. [CrossRef] 
22. Li, Y. The anisotropic behavior of Poisson's ratio, Young's modulus, and shear modulus in hexagonal materials. Phys. Status Solidi Appl. Res. 1976, 38, 171-175. [CrossRef]

23. Yeganeh-Haeri, A.; Weidner, D.J.; Parise, J.B. Elasticity of $\alpha$-cristobalite: A silicon dioxide with a negative poisson's ratio. Science 1992, 257, 650-652. [CrossRef]

24. Liu, Q. Literature Review: Materials with Negative Poisson's Ratios and Potential Applications to Aerospace and Defence; Defence Science and Technology Organisation: Canberra, Australia, 2006.

25. Faisal, N.; Mcleod, A.; Booth, F.; Scott, L.; Duncan, S.; Droubi, G. Auxetic Structures for Marine Safety Applications (Rope, Sandwich Panel). Presented at the The Institute of Marine Engineering, Science and Technology (IMarEST), Londin, UK, 28 March 2018.

26. Uzun, M. Mechanical Properties of Auxetic and Conventional Polypropylene Random Short Fibre Reinforced Composites. Fibres Text. East. Eur. 2012, 5, 70-74.

27. Miller, W.; Ren, Z.; Smith, C.; Evans, K. A negative Poisson's ratio carbon fibre composite using a negative Poisson's ratio yarn reinforcement. Compos. Sci. Technol. 2012, 72, 761-766. [CrossRef]

28. Wang, X.-T.; Wang, B.; Wen, Z.-H.; Ma, L. Fabrication and mechanical properties of CFRP composite three-dimensional doublearrow-head auxetic structures. Compos. Sci. Technol. 2018, 164, 92-102. [CrossRef]

29. Pozniak, A.; Wojciechowski, K.W.; Grima, J.; Mizzi, L. Planar auxeticity from elliptic inclusions. Compos. Part B Eng. 2016, 94 , 379-388. [CrossRef]

30. Narojczyk, J.W.; Wojciechowski, K.W. Poisson's Ratio of the f.c.c. Hard Sphere Crystals with Periodically Stacked (001)-Nanolayers of Hard Spheres of Another Diameter. Materials 2019, 12, 700. [CrossRef]

31. Brańka, A.C.; Heyes, D.M.; Wojciechowski, K.W. Auxeticity of cubic materials under pressure. Phys. Status Solidi B 2011, 248, 96-104. [CrossRef]

32. Hu, H. Auxetic Textile Materials-A review. J. Text. Eng. Fash. Technol. 2017, 1, 1-15. [CrossRef]

33. Argatov, I.; Guinovart-Díaz, R.; Sabina, F. On local indentation and impact compliance of isotropic auxetic materials from the continuum mechanics viewpoint. Int. J. Eng. Sci. 2012, 54, 42-57. [CrossRef]

34. Yang, W.; Li, Z.-M.; Shi, W.; Xie, B.-H.; Yang, M.-B. On auxetic materials: Review. J. Mater. Sci. 2004, 39, 3269-3280. [CrossRef]

35. Evans, K.E.; Alderson, K.L. Auxetic materials: The positive side of being negative. Eng. Sci. Educ. J. 2000, 9, 148-154. [CrossRef]

36. Alderson, K.L.; Alderson, A.; Smart, G.; Simkins, V.R.; Davies, P.J. Auxetic polypropylene fibres: Part 1-Manufacture and characterisation. Plast. Rubber Compos. 2002, 31, 344-349. [CrossRef]

37. Lakes, R.S.; Witt, R. Making and Characterizing Negative Poisson's Ratio Materials. Int. J. Mech. Eng. Educ. 2002, 30, 50-58. [CrossRef]

38. Lorato, A.; Innocenti, P.; Scarpa, F.; Alderson, A.; Alderson, K.; Zied, K.; Ravirala, N.; Miller, W.; Smith, C.; Evans, K. The transverse elastic properties of chiral honeycombs. Compos. Sci. Technol. 2010, 70, 1057-1063. [CrossRef]

39. Mir, M.; Ali, M.N.; Sami, J.; Ansari, U. Review of Mechanics and Applications of Auxetic Structures. Adv. Mater. Sci. Eng. 2014, 2014, 1-18. [CrossRef]

40. Alderson, K.; Webber, R.; Mohammed, U.; Murphy, E.; Evans, K. An experimental study of ultrasonic attenuation in microporous polyethylene. Appl. Acoust. 1997, 50, 23-33. [CrossRef]

41. Darja, R.; Tatjana, R.; Alenka, P.Č. Auxetic textiles. Acta Chim. Slov. 2013, 60, 715-723.

42. Ng, W.S.; Hu, H. Woven fabrics made of auxetic plied yarns. Polymers 2018, 10, 226. [CrossRef] [PubMed]

43. Sloan, M.; Wright, J.; Evans, K. The helical auxetic yarn-A novel structure for composites and textiles; Geometry, manufacture and mechanical properties. Mech. Mater. 2011, 43, 476-486. [CrossRef]

44. Miller, W.; Hook, P.; Smith, C.W.; Wang, X.; Evans, K.E. The manufacture and characterisation of a novel, low modulus, negative Poisson's ratio composite. Compos. Sci. Technol. 2009, 69, 651-655. [CrossRef]

45. Yang, S.; Chalivendra, V.B.; Kim, Y.K. Impact behaviour of auxetic Kevlar ${ }^{\circledR} /$ epoxy composites. In IOP Conference Series: Materials Science and Engineering; IOP Publishing: Bristol, UK, 2017. [CrossRef]

46. Khan, M.I.; Akram, J.; Umair, M.; Hamdani, S.T.A.; Shaker, K.; Nawab, Y.; Zeeshan, M. Development of composites, reinforced by novel 3D woven orthogonal fabrics with enhanced auxeticity. J. Ind. Text. 2019, 49, 676-690. [CrossRef]

47. Rabbi, F.; Chalivendra, V.; Kim, Y. Dynamic constitutive response of novel auxetic Kevlar ${ }^{\circledR}$ /epoxy composites. Compos. Struct. 2018, 195, 1-13. [CrossRef]

48. Hu, H.; Zhang, M.; Liu, Y. Auxetic fibre-reinforced composites. Auxetic Text. 2019, 1, 285-335. [CrossRef]

49. Zhou, L.; Jiang, L.; Hu, H. Auxetic composites made of 3D textile structure and polyurethane foam. Phys. Status Solidi Basic Res. 2016, 253, 1331-1341. [CrossRef]

50. Pan, N. Analysis of woven fabric strengths: Prediction of fabric strength under uniaxial and biaxial extensions. Compos. Sci. Technol. 1996, 56, 311-327. [CrossRef]

51. Cao, H.; Zulifqar, A.; Hua, T.; Hu, H. Bi-stretch auxetic woven fabrics based on foldable geometry. Text. Res. J. 2019, 89, 2694-2712. [CrossRef]

52. Grima, J.N.; Ravirala, N.; Galea, R.; Ellul, B.; Attard, D.; Gatt, R.; Alderson, A.; Rasburn, J.; Evans, K.E. Modelling and testing of a foldable macrostructure exhibiting auxetic behaviour. Phys. Status Solidi Basic Res. 2011, 248, 117-122. [CrossRef] 
53. Whitcomb, J.D.; Chapman, C.D.; Tang, X. Derivation of boundary conditions for micromechanics analyses of plain. J. Compos. Mater. 2000, 34, 724-747. [CrossRef]

54. Carvelli, V.; Corazza, C.; Poggi, C. Mechanical modelling of monofilament technical textiles. Comput. Mater. Sci. $2008,42,679-691$. [CrossRef] 